\title{
Brassinosteroid analogue affects the senescence in two papaya genotypes submitted to drought stress
}

\section{Mara de Menezes de Assis Gomes ${ }^{1}$, Alena Torres Netto', Eliemar Campostrini', Ricardo Bressan-Smith', Marco António Teixeira Zullo², Tiago Massi Ferraz', Luciane do Nascimento Siqueira', Nilton Rocha Leal', Miriam Núñez-Vázquez ${ }^{3}$}

'Setor de Fisiologia Vegetal, Universidade Estadual do Norte Fluminense, Campos dos Goytacazes, RJ, Brazil.

${ }^{2}$ Laboratório de Fitoquímica, Instituto Agronômico de Campinas, Campinas, SP, Brazil.

${ }^{3}$ Instituto Nacional de Ciencias Agrícolas, La Habana, Cuba.

*Corresponding author: maramag@ig.com.br

Received: 20 December 2012; Accepted: 26 September 2013

ABSTRACT: Brassinosteroids (BS) application is associated with the increase of tolerance to some kinds of stresses, such as those induced by the infection of pathogens, temperature, salt and water deficiency. In this work, the influence of a spirostanic analogue of brassinosteroid (SAB) in the leaves of papaya Golden and UENF/CALIMAN 01 (UC 01) was tested to evaluate alterations in the content of chlorophyll in plants submitted to drought stress (DS). When plants were $70 \mathrm{~d}$ old, SAB was applied $\left(0,1 \mathrm{mg} \mathrm{L}^{-1}\right)$ for five consecutive days in half of the plants meant for the experiment. The treatments were: control irrigated (I), I with SAB (IB), DS and DS with SAB (DSB). The evaluated leaves were marked in accordance to the age: LEAF 1 (youngest expanded leaf), LEAF 2 (insertion immediately below LEAF 1) and LEAF 3 (insertion immediately below LEAF 2). The same leaves were used throughtout the experimental period. After the thirteenth day, the chlorophyll contents of DSB (Golden and UC 01) were always lesser than the treatment DS in LEAF 2. The irrigation was restarted in stressed plants on the fifteenth day, followed by new application of SAB (IB and DSB treatments). In Golden plants, DSB showed the lowest values of chlorophyll contents after re-watering, while in UC 01, differences in chlorophyll contents between treatments DS and DSB had not occurred. Alterations in $\mathrm{F}_{\mathrm{v}} / \mathrm{F}_{\mathrm{m}}$ relation did not occur among the treatments during stress. In genotype UC 01, the irrigated plants showed minor values of $F_{v} / F_{m}$ at the end of the experiment, whereas the plants submitted to DS presented increments in this relation in this same time. These results indicate that SAB might have contributed to accelerate the rate of leaf senescence of the oldest leaves of stressed plants, redistributing photoassimilates and other compounds for the youngest leaves.

KEYWORDS: chlorophyll content, Carica papaya L., fluorescence, water relations.

\section{INTRODUCTION}

Leaf senescence is a structurally, physiologically and genetically coordinated process, where organelles and their constituents are sequentially broken down and the nutrients released are recycled by organs that are growing actively, such as young leaves and fruits (Noodén 1988). Leaf senescence is guided by changes in gene expression. A majority of genes that are active in non-senescent leaves, such as those involved in photosynthesis, are repressed while other genes, such as senescence-associated genes (SAGs), are upregulated (He et al.2001). Physiological and biochemical studies suggest that leaf senescence is regulated by certain endogenous and environmental factors (Noodén 1988, Smart 1994), including abiotic and biotic factors such as drought, nutrient limitation, extreme temperature, and oxidative stress by UV-B irradiation and ozone (Lim et al. 2007).

Brassinosteroids (BS) are endogenous plant growth-promoting hormones that act on plant development and affect numerous physiological processes at low concentrations (Mandava 1988, Müssig and Altmann 1999, Zullo and Adam 2002), and senescence is a developmentally regulated and genetically programmed process that may be mediated by brassinosteroids (Zhao et al. 1990, He et al. 1996, Li et al. 1996, Clouse and Sasse 1998, Vardhini and Rao 2002). Brassinosteroids induced senescence 
in detached cotyledons of cucumber seedlings (Zhao et al. 1990) and leaves of mung bean seedlings (He et al. 1996). Additionally, Arabidopsis mutants lacking bioactive brassinosteroids show delay in chloroplast senescence (Li et al. 1996). Other studies involving brassinosteroids have emphasized the potential of these substances in protecting the plants against several stresses, including cold, herbicides (Khripach et al. 2000), heat (Dhaubhadel et al. 2002), diseases (Nakashita et al. 2003), drought stress, low temperature and salinity stress (Kagale et al. 2007). The BS increase is generally correlated with higher expression of stress marker genes, such as heat shock protein (hsp) genes, like RD29A and ERD10 (Dhaubhadel etal. 1999, Kagale et al. 2007), indicating that increased expression of stress-responsive genes is responsible, in part, for the higher stress tolerance in BR-treated plants (Divi et al. 2010).

Water stress is one of the most deleterious stresses for plants; its occurrence invariably leads to physiological changes like stomatal closure, leaf abscission, composition of cell wall and plasma membrane with a decline on photosynthesis and growth (Jager et al. 2008). In some instances, brassinosteroids have been suggested to confer tolerance of plant to water stress (Zhang et al. 2008, Li et al. 2008). In soybean (Glycine max L.), brassinolide applied at the beginning of bloom on plants subjected to water stress, enhanced drought tolerance and minimized yield loss (Zhang et al. 2008). In Robinia pseudoacacia seedlings, soaking roots in brassinolide prior to planting increased the peroxidase, superoxide dismutase and catalase activities in water stressed plants when compared to control plants (Li et al. 2008).

Papaya (Carica papaya L.) is a semi-woody giant herb, and this species is considered to be drought sensitive and responsive to irrigation (Carr 2013), so soil water availability limits many physiological processes of papaya (Marler et al. 1994, Clemente and Marler 1996, Mahouachi et al. 2007). The irrigation of papaya plants is recommended during dry periods to increase growth and fruit production (Malo and Campbell 2006) whereas incorrect water management can adversely affect several physiological processes (Campostrini and Glenn 2007, Campostrini et al. 2010). Mahouachi et al. $(2006,2007,2012)$ reported that papaya responds to drought by decreasing plant growth and leaf gas exchange parameters and promoting leaf abscission. Mahouachi et al. (2007) suggest that abscisic acid ( $\mathrm{ABA}$ ) could be involved in the induction of several progressive responses such as the induction of stomatal closure and leaf abscission to reduce papaya water loss.

Different plant hormones can regulate altogether the same physiological process, and crosstalk between them can occur at the level of hormone biosynthesis, signal transduction or gene expression (Nemhauser et al. 2006). It has been proposed that
BS regulates plant stress responses via crosstalk with other hormones (Krishna 2003). Divi et al. (2010) showed that $\mathrm{ABA}$ suppresses $\mathrm{BR}$ effects on thermo-tolerance, but BR may enhance $A B A$ responses under certain conditions by increasing ABA levels.

We hypothesized that the application of BS in papaya leaves of plants subjected to water stress can affect the chlorophyll content (leaf senescence) and photochemical efficiency. In addition, intra-specific variability at BR response in papaya genotypes subjected to progressive water stress can be verified.

\section{MATERIAL AND METHODS}

Experiment Conditions: Two Carica papaya genotypes, UENF-CALIMAN (UC 01) and Golden, were planted in polystyrene trays using Plantmax as a substrate. After $33 \mathrm{~d}$, the plantlets were transferred to $10 \mathrm{~L}$ pots filled with soil, sand and manure mixture (1:2:1). The following treatments were applied $70 \mathrm{~d}$ after seedling: Irrigated control (I), irrigated control with BS application (IB), drought stress (DS), and drought stress with BS application (DSB). The brassinosteroid used was a spirostanic analogue of brassinosteroid - BIOBRAS-16

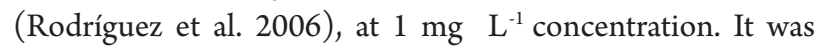
sprayed on the leaves at 5:00 p.m. for five consecutive days before the drought stress treatment and on the day of rewatering ( $15 \mathrm{~d}$ after water suspension). When the available water in the substrate was below $10 \%$, the plants subjected to drought stress were rewatered. The leaves were marked as LEAF 1 (the youngest fully expanded leaf close to the apex), LEAF 2 (the first mature leaf immediately below the insertion of LEAF 1), and LEAF 3 (the second mature leaf immediately below the insertion of LEAF 2). The chlorophyll fluorescence and relative water content measurements were carried out only on LEAF 1, while chlorophyll content measurements were assayed for leaves 1,2 and 3. For each treatment, twenty plants were used (eighty plants for each genotype). At the beginning of the experiment, all the plants were uniform in leaf number and height. The leaves used in this experiment remained exactly the same during the whole period, independent of the appearance of younger leaves.

Soil Moisture: The soil moisture (SM) was determined three times throughout the experiment (eleven and fifteen days after water withholding and nine days after rewatering). Soil samples were collected and placed into pots to obtain the fresh mass (FM). After $72 \mathrm{~h}$ at $100^{\circ} \mathrm{C}$, the dry mass (DM) was obtained by weighing the pots. The percent humidity was calculated using the formula, $\mathrm{SM}=[(\mathrm{FM}-\mathrm{DM}) / \mathrm{DM}]^{*} 100$. 
Relative Water Content: Leaf discs were taken at eleven and fifteen days after water suspension and nine days after rewatering. The relative water content (RWC) was calculated using five leaf discs (from LEAF 1) that were cut and sequentially weighed (fresh mass, FM), maintained under light for $24 \mathrm{~h}$ in a flask with water to achieve saturation (turgid mass, $\mathrm{TM}$ ), and oven-dried at $80^{\circ} \mathrm{C}$ for $48 \mathrm{~h}$ (dry mass, DM). The relative water content was calculated using the formula, RWC $(\%)=[(\mathrm{FM}-\mathrm{DM}) /(\mathrm{TM}-\mathrm{DM})]^{*} 100$.

Chlorophyll Fluorescence: The chlorophyll $a$ fluorescence parameters were determined using a non-modulated fluorimeter PEA (Plant Efficiency Analyzer, Hansatech Ltd., King's Lynn, UK) on LEAF 1 (three plants for each treatment). The leaves were pre-darkened for $30 \mathrm{~min}$ so that all reaction centers were 'open' (all primary acceptors oxidized) and heat dissipation was minimal. After dark adaptation, the chlorophyll fluorescence variables, $\mathrm{F}_{\mathrm{o}}$ (initial fluorescence) and $\mathrm{F}_{\mathrm{m}}$ (maximum fluorescence) were obtained, and $\mathrm{F}_{\mathrm{v}}$ (variable fluorescence - the difference between $\mathrm{F}_{0}$ and $\mathrm{F}_{\mathrm{m}}$ ) and $\mathrm{F}_{\mathrm{v}} / \mathrm{F}_{\mathrm{m}}$ (maximum quantum yield) were determined.

Green Leaf Colour Intensity: The green leaf colour intensity was determined using a portable chlorophyll meter model, SPAD-502 (Minolta, Japan). The measurements were performed over two days for both genotypes. Five readings from each leaf (LEAF 1, 2 and 3) were performed using three plants per treatment.

Leaf Area and Shoot Dry Matter. At eleven and fifteen days after water suspension and nine days after rewatering, the leaves were removed from the stem and the root, and the leaf area was measured using a leaf area meter (LAI 6200, Licor, USA). The leaves were oven-dried at $80^{\circ} \mathrm{C}$ for $48 \mathrm{~h}$ to obtain the shoot dry mass (three plants per treatment).

Statistical analysis: The data were analyzed using an ANOVA analysis and the means were compared by the Tukey test (5\%) using the SAEG system.

\section{RESULTS}

Eleven days after imposing a water stress, the droughtstressed treatments showed soil moisture values below $10 \%$ for UC 01 genotype (Table 1). Fifteen days after imposing the water stress, the soil moisture for drought-stressed treatments was approximately $7.5 \%$, while the irrigated substrate was above $25 \%$. Nine days after rewatering, the plants subjected to water deficiency showed soil moisture of approximately $20 \%$ independent of the use of brassinosteroid. These values were lower than the irrigated plants, which kept the soil moisture above $25 \%$. The SAB application did not alter the soil moisture of irrigated plants or plants subjected to water deficiency. Thus, the soil moisture was only altered by drought.

In the UC 01 genotype, significant differences in the RWC of LEAF 1 were observed during the first day of measurements (Table 1). On this day, the DS plants showed the highest RWC values, while the irrigated plants showed the lowest. However, on the other days, it was not possible to identify significant variation in RWC among the different treatments.

LEAF 1 from the irrigated plants was the most mature leaf on these plants because the development of new leaves was not observed. Furthermore, in the drought stressed plants, the development of new leaves completely stopped. Thus, LEAF 1 from these plants continued to be the youngest leaf, although it was the most mature, as the formation of new leaves was not observed.

In the UC 01 genotype, the plants that were subjected to water deficiency still had shoot dry mass lower than that of the irrigated plants, even after the end of water deficiency. It is important to note that after rewatering, the stressed plants lost senescent leaves faster, even losing leaves near the apex of the plant.

At day eleven, the soil moisture of the drought stressed Golden plants were dryer (16 and $11 \%$ to DS and DSB plants, respectively) than the irrigated substrate, which was approximately $31 \%$ (Table 1). On day fifteen of the

Table 1. Soil moisture and effects of drought stress and brassinosteroid analogue application on the relative water content of leaves (RWC), leaf area and shoot dry mass of papaya plants (genotype UC 01) in relation to days after beginning of water drought. Rewatering is indicated as 'rew'

\begin{tabular}{|c|c|c|c|c|}
\hline UC 01 & I & IB & DS & DSB \\
\hline \multicolumn{5}{|c|}{ Soil moisture (\%) } \\
\hline $11 \mathrm{~d}$ & 29,7 a & $23,6 \mathrm{a}$ & $8,6 \mathrm{~b}$ & $10,0 \mathrm{~b}$ \\
\hline $15 d$ & $30,0 \mathrm{a}$ & 29,0 a & $8,0 \mathrm{~b}$ & $8,0 \mathrm{~b}$ \\
\hline $9 \mathrm{~d}$ after rew & 30,0 a & $26,0 \mathrm{a}$ & $18,8 \mathrm{~b}$ & $21,0 \mathrm{~b}$ \\
\hline \multicolumn{5}{|l|}{ RWC (\%) } \\
\hline $11 \mathrm{~d}$ & $80,5 a$ & $80,0 \mathrm{a}$ & 77,5 a & $74,6 a$ \\
\hline $15 d$ & $83,4 a$ & $83,6 a$ & 81,6 a & $83,2 a$ \\
\hline $9 \mathrm{~d}$ after rew & $88,7 \mathrm{a}$ & 88,0 a & 90,3 a & $84,4 a$ \\
\hline \multicolumn{5}{|l|}{ Leaf area $\left(\mathrm{mm}^{2}\right)$} \\
\hline $11 \mathrm{~d}$ & 2889,3 a & $2839,3 \mathrm{a}$ & $2162,7 \mathrm{~b}$ & $2003,8 b$ \\
\hline $15 d$ & 3470,9 a & $3418,5 \mathrm{a}$ & $1001,6 \mathrm{~b}$ & $1307,1 \mathrm{~b}$ \\
\hline $9 \mathrm{~d}$ after rew & $2835,2 \mathrm{a}$ & 2530,6 a & $1512,7 \mathrm{~b}$ & 1953,6 b \\
\hline \multicolumn{5}{|c|}{ Shoot dry mass (g) } \\
\hline $11 \mathrm{~d}$ & $25,9 a$ & $25,4 a$ & $25,2 \mathrm{a}$ & $20,0 a$ \\
\hline $15 d$ & $31,7 \mathrm{a}$ & $28,0 \mathrm{a}$ & $20,3 \mathrm{~b}$ & $21,9 \mathrm{~b}$ \\
\hline $9 \mathrm{~d}$ after rew & $31,7 \mathrm{a}$ & $30,7 \mathrm{a}$ & $21,3 \mathrm{~b}$ & $23,8 b$ \\
\hline
\end{tabular}

I: irrigated, IB: irrigated with brassinosteroids, DS: Drought stress, DSB: Drought stress with brassinosteroids. Means followed by the same letter in the same line are not significantly different, Tukey test, $5 \%$. 
drought stress, the soil moisture of DS and DSB plants was approximately $8.5 \%$. Nine days after rewatering, there were no significant differences in soil moisture between the treatments.

The relative water content of leaves from the Golden did not show differences among the treatments during the experiment (Table 2).

The leaf area of the Golden genotype plants did not show significant differences among the four treatments eleven days after water stress (Table 2). On the fifteenth day of water deficiency, the plants subjected to drought stress from both genotypes completely stopped growing, with no leaf emissions and almost all of the basal leaves falling off. This reduction in leaf area happened because of the accelerated senescence in the basal leaves as a result of intense stress. Thus, only the leaves from the apex showed green and turgid leaves.

Only after $15 \mathrm{~d}$ of water deficiency, the shoot dry matter had decreased for both genotypes. Meanwhile, the Golden genotype plants showed dry mass values different from the values measured for irrigated plants without $\mathrm{SAB}$ after rewatering.

Irrigated plants tend to decrease the chlorophyll content of senescing leaves (Figure 1A). During the $24 \mathrm{~d}$ experiment, the UC 01 irrigated plants decreased the LEAF 1 SPAD values from 43 to 33. Similar results were also observed on the DSB plants. It is interesting that the leaves measured in DS treatments were the only ones that remained on these plants as

Table 2. Soil moisture and effects of drought stress and brassinosteroid analogue application on the relative water content of leaves (RWC), leaf area and shoot dry mass of papaya plants (genotype Golden) in relation to days after beginning of water drought. Rewatering is indicated as 'rew'

\begin{tabular}{|c|c|c|c|c|}
\hline GOLDEN & 1 & IB & DS & DSB \\
\hline \multicolumn{5}{|c|}{ Soil moisture (\%) } \\
\hline $11 \mathrm{~d}$ & $31,3 \mathrm{a}$ & $31,6 \mathrm{a}$ & $16,1 \mathrm{~b}$ & $11,0 \mathrm{~b}$ \\
\hline $15 d$ & $31,8 \mathrm{a}$ & $30,1 \mathrm{a}$ & $9,1 \mathrm{~b}$ & $8,9 b$ \\
\hline $9 \mathrm{~d}$ after rew & 22,8 a & $23,7 \mathrm{a}$ & $20,8 \mathrm{a}$ & $23,0 a$ \\
\hline \multicolumn{5}{|l|}{ RWC (\%) } \\
\hline $11 \mathrm{~d}$ & $78,0 \mathrm{a}$ & $78,6 \mathrm{a}$ & $81,3 \mathrm{a}$ & $80,4 a$ \\
\hline $15 d$ & 81,9 a & $84,7 \mathrm{a}$ & $80,1 \mathrm{a}$ & $82,5 a$ \\
\hline $9 \mathrm{~d}$ after rew & 79,6 a & 80,0 a & 76,8 a & 79,1 a \\
\hline \multicolumn{5}{|l|}{ Leaf area $\left(\mathrm{mm}^{2}\right)$} \\
\hline $11 \mathrm{~d}$ & 1597,6 a & $2131,0 \mathrm{a}$ & 1502,5 a & $1619,1 \mathrm{a}$ \\
\hline $15 d$ & 2122,9 a & 2360,4 a & $1586,6 \mathrm{~b}$ & $1460,2 \mathrm{~b}$ \\
\hline $9 \mathrm{~d}$ after rew & 2484,0 a & $2161,5 \mathrm{a}$ & $1530,2 b$ & $1596,0 \mathrm{~b}$ \\
\hline \multicolumn{5}{|c|}{ Shoot dry mass $(\mathrm{g})$} \\
\hline $11 d$ & $10,72 \mathrm{a}$ & 14,34 a & 9,4 a & $10,6 \mathrm{a}$ \\
\hline $15 d$ & $15,5 \mathrm{a}$ & $16,2 \mathrm{a}$ & $11,2 \mathrm{~b}$ & $10,1 \mathrm{~b}$ \\
\hline $9 \mathrm{~d}$ after rew & $22,1 \mathrm{a}$ & $17,8 a b$ & $14,9 \mathrm{~b}$ & $16,8 \mathrm{ab}$ \\
\hline
\end{tabular}

I: irrigated, IB: irrigated with brassinosteroids, DS: Drought stress, DSB: Drought stress with brassinosteroids. Means followed by the same letter in the same line are not significantly different, Tukey test, $5 \%$. the old leaves abscised. Thus, these leaves played an important role in supplying $\mathrm{CO}_{2}$ to the leaflets.

On LEAF 2, the effects of SAB application on the DSB UC 01 plants were noticed from the first day after rewatering and after the second $S A B$ application. The leaf senescence process in the plants receiving the $S A B$ treatment was intensified in drought-stressed plants, while the chlorophyll content was unaltered in the other treatments. The water stress in the DS plants, however, stabilized the decrease of chlorophyll content. The irrigated plants, I and IB, showed the same profile of decreasing chlorophyll content during the experiment (Figure 1B). The DSB plants had a different profile because the $S A B$ was applied at the same time as rewatering, which led to an anticipation of the senescence process. It is well known that BS can stimulate ethylene synthesis in some conditions, which might have occurred in this case. The acceleration of senescence in the DSB treatments could be related to the distribution of photoassimilates in the youngest leaves.

For LEAF 3, the second SAB application did not cause any effects in the DSB and IB plants (Figure 1C). The leaves from the DS and DSB treatments were most likely exporting carbon reserves to younger leaves. LEAF 3 from the irrigated plants showed the highest decrease in chlorophyll content.

The Golden genotype plants showed no differences in chlorophyll content in LEAF 1 between the treatments (Figure 2A). The SPAD values varied from 42 to 29 . The effects of SAB application on LEAF 2 were observed in the DSB plants because they were different from the decrease in chlorophyll content in the DS plants (Figure 2B).

The $\mathrm{SAB}$ application accelerated the senescence rate of the DSB plants and the second application ofSAB intensified the decrease in chlorophyll content after rewatering. There were no effects of the $S A B$ application on the irrigated plants.

For LEAF 3, as was observed for LEAF 2, the DSB treatment showed lower chlorophyll content than the other treatments on the thirteenth day of water deficiency (Figure 2C). Only on the fifteenth day did the DS plants show lower chlorophyll content values than the irrigated plants. The irrigated plants did not show any difference in chlorophyll content throughout the experiment. After the SAB application and water stress, we verified that the DSB plants showed the lowest chlorophyll content values and that the DS plants showed intermediate values between the irrigated treatment and the drought-stressed $S A B$ treatment until the ninth day after rewatering.

The Golden leaves from DSB treatment showed the highest $\mathrm{F}_{\mathrm{v}} / \mathrm{F}_{\mathrm{m}}$ ratio relative to the other treatments (Figure $3 \mathrm{~A}$ ). This might have happened because LEAF 1 senesced on the 
irrigated plants, while maintaining turgor on the stressed plants. The vegetative growth of the stressed plants stopped as the stress conditions were increased, while the vegetative growth of irrigated plants increased during those $15 \mathrm{~d}$ and the leaves triggered the senescence process.

During the water deficiency period $(15 \mathrm{~d})$, it was not possible to verify damage in the photosynthetic machinery of LEAF 1 from the UC 01 treatments (Figure 3B). Nevertheless, it was possible to verify that plants subjected to drought stress showed higher $\mathrm{F}_{\mathrm{v}} / \mathrm{F}_{\mathrm{m}}$ values than the plants from irrigated treatments, one day after rewatering. The $\mathrm{SAB}$ application on irrigated plants decreased the $\mathrm{F}_{\mathrm{v}} / \mathrm{F}_{\mathrm{m}}$ ratio when compared to the irrigated treatment without $\mathrm{SAB}$.

\section{DISCUSSION}

Senescence is controlled by phytohormones and the involvement of auxins, ethylene and cytokinins is well documented. However, it is likely that BS influences this process. In our experiment, the involvement of brassinosteroids on senescence (breakdown of chlorophyll) was verified in younger leaves (LEAF 1) of genotype UC 01, independently of water stress. In older leaves of this genotype (LEAF 3), independently of brassinosteroid application, there was a reduction on chlorophyll content in both drought-stressed treatments. Çăg (2007) showed that epi-brassinolide (EBL) accelerated senescence in wheat (Triticum aestivum L.) leaf segments, especially at high concentrations. An increase in

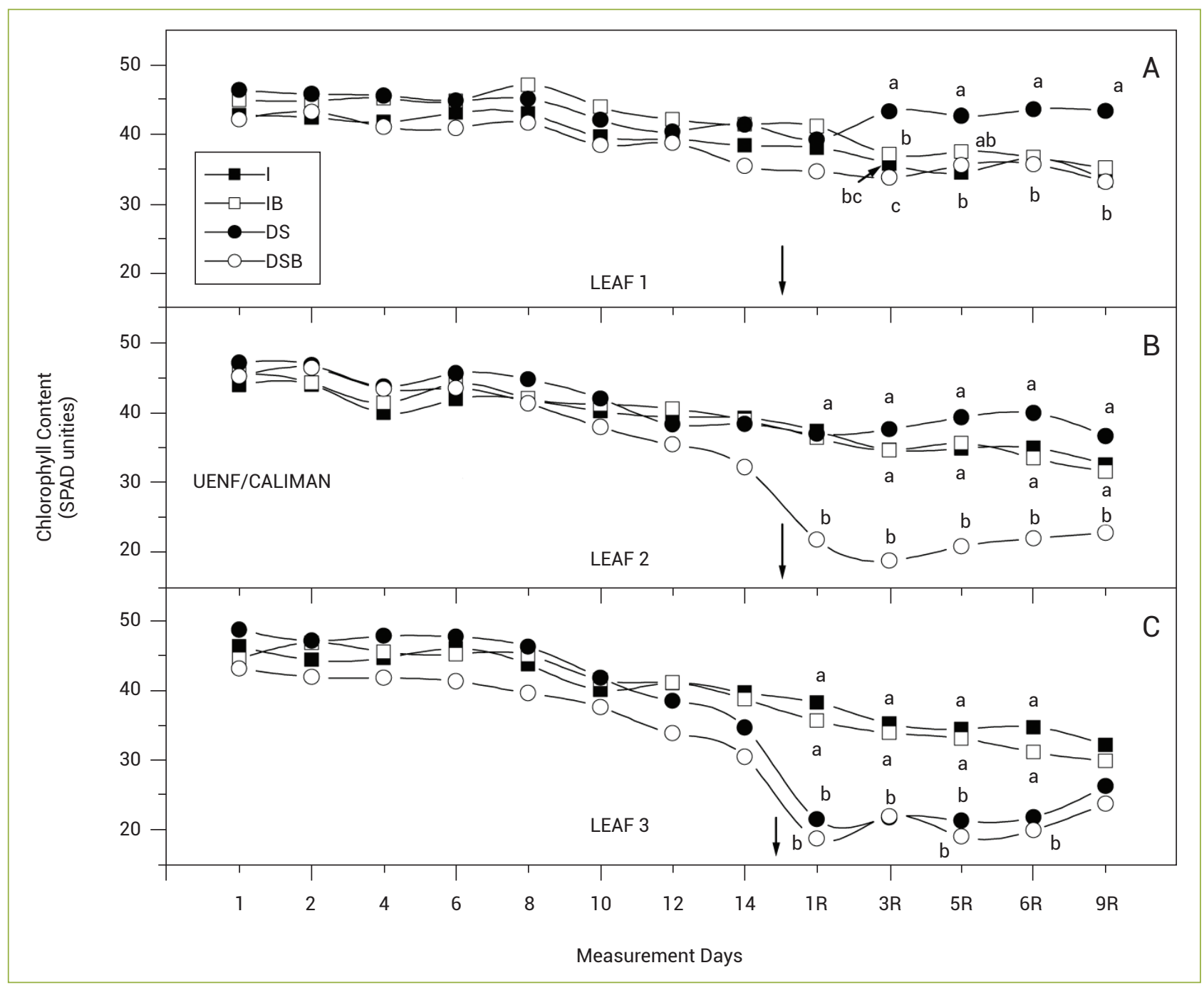

Figure 1. Effects of drought stress and brassinosteroid application on the chlorophyll content of leaves from genotype UC 01 . LEAF 1 (youngest expanded leaf), LEAF 2 (leaf insertion immediately below LEAF 1) and LEAF 3 (leaf insertion immediately below LEAF 2). Arrow indicates rewatering day and SAB application. $\mathrm{R}$ indicates days after rewatering. (I: irrigated, IB: irrigated with brassinosteroids, DS: Drought stress, DSB: Drought stress with brassinosteroids). Means followed by the same letters are not significantly different, Tukey test, $5 \%$. 
peroxidase activity (at $0.1 \mu \mathrm{M}$ ) and a decrease in protease activity (at $10 \mu \mathrm{M}$ ) were detected. Application of 0.1 and $10 \mu \mathrm{M}$ were effective in accelerating chlorophyll breakdown, while $0.001 \mu \mathrm{M}$ EBL treatment showed the highest chlorophyll content in leaves due to inhibition of chlorophyll loss. Thus, senescence can be accelerated or delayed by brassinosteroid in a dose-dependent manner. The loss of pigments may be considered as an indicator of water deficiency and senescence in papaya (Campostrini and Glenn 2007). In papaya, especially the genotypes used in this experiment (UC 01 and Golden), the chlorophyll content can be estimated by SPAD readings as a high correlation between these parameters were demonstrated (Torres-Netto et al. 2002, 2009). The fact that brassinosteroid-treated leaves of irrigated plants did not alter chlorophyll content even on older leaves, might be related to the fact that brassinosteroid acts on senescence after a triggering event. In this experiment, water stress was the trigger of senescence process. Behnamnia et al. (2009) verified that carotenoid content was significantly higher in BS-treated tomato plants under drought stress compared to control plant. Brassinosteroids have antioxidative characteristics as the activity of antioxidant enzymes and antioxidative compounds (ascorbate, carotenoids and proline) are usually observed after treatment with BS (Gomes 2011).

It is possible that the increase in the rate of senescence of older leaves in the plants subjected to water deficiency and treated with BRs was most likely higher due to the induction of senescence promoted by the increase of abscisic acid content. It is known that

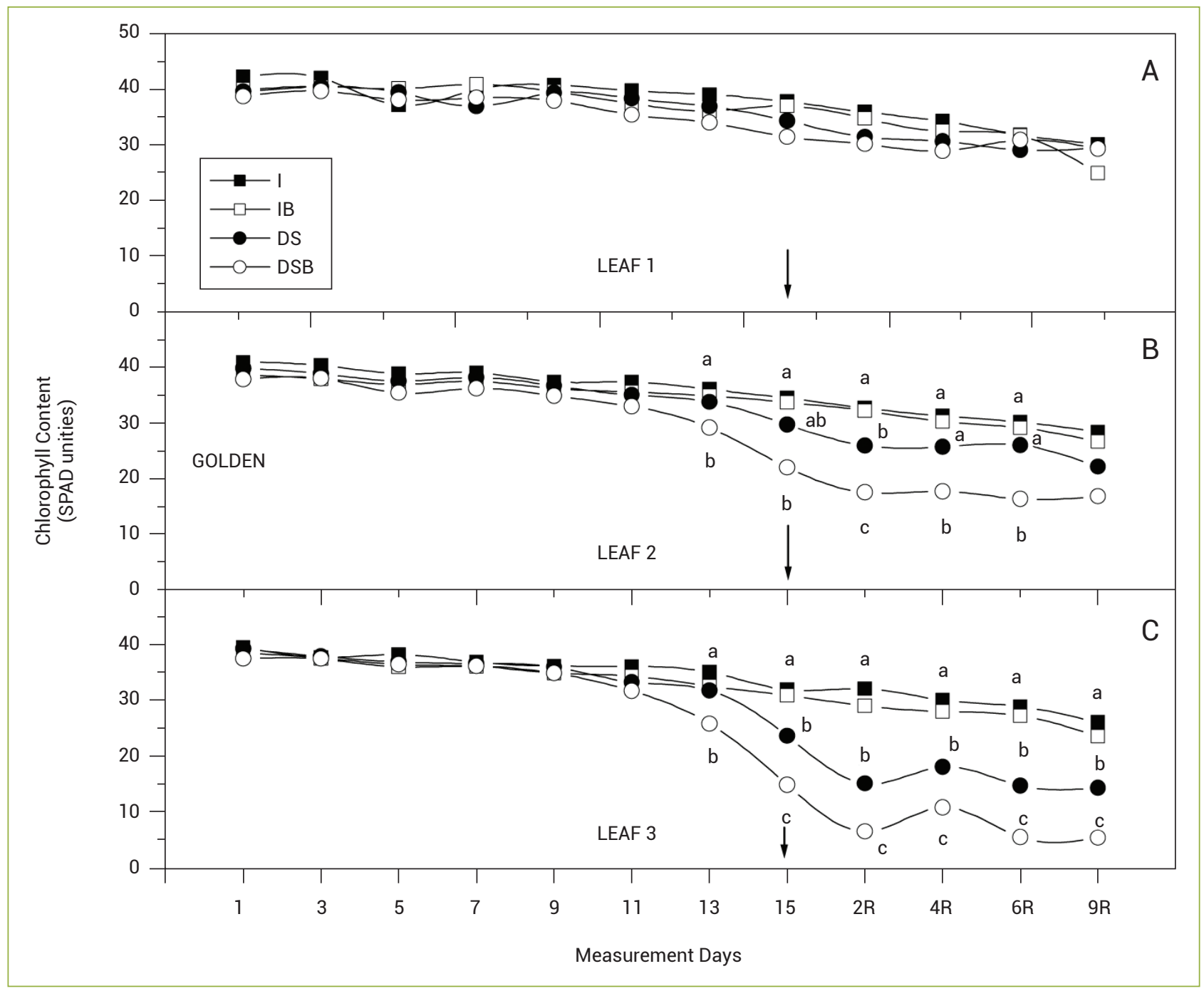

Figure 2. Effects of drought stress and brassinosteroid application on the chlorophyll content (SPAD unities) of leaves from genotype Golden. LEAF 1 (youngest expanded leaf), LEAF 2 (leaf insertion immediately below LEAF 1) and LEAF 3 (leaf insertion immediately below LEAF 2). Arrow indicates re-watering day and SAB application. R indicates days after rewatering. (I: irrigated, IB: irrigated with brassinosteroids, DS: Drought stress, DSB: Drought stress with brassinosteroids). Means followed by the same letters are not significantly different, Tukey test, $5 \%$. 
an increase in abscisic acid occurs naturally in plants subjected to water deficiency, and increased ethylene content in the leaves might be promoted by the presence of brassinosteroids.

The development of papaya plants is very peculiar. Despite being a dicot, this plant does not emit branches but emits leaves in a spiral around the stem. Therefore, it is easy to accurately determine the age of leaves and predict the emergence of new leaves. When the plant is severely water stressed, only the newest leaves at the apex of the plant remain while the older leaves, located near the basal region, go through senescence and abscission. In our experiment, the chlorophyll content was analyzed in the leaves located at the apex of the plant, those which remained when the plants were water stressed. It is important to notice that newer leaves developed in non-stressed plants. Papaya plants have a tendency to manage water, nutrients and other metabolites to the youngest leaves and eliminate the older ones during stress to decrease the transpiration area. For this reason, the youngest leaves from the drought-treated plants kept their turgor longer, while the older leaves senesced and abscised. The SAB application did not affect the relative water content of LEAF 1 of irrigated and non-irrigated plants. It is important to notice that on both genotypes the leaves sampled were the ones that remained fixed on the plant even during the drought treatments.

Mutants of Arabidopsis that do not have brassinosteroids display an active delay in the senescence of leaves ( $\mathrm{Li}$ et al. 1996). However, other authors have reported that the application of brassinosteroids caused a delay in senescence and abscission of leaves and fruits in citrus (Sugiyama and Kuraishi 1989; Iwahori 1990) and in the hypocotyl segments of seedlings of Vigna radiata (Zhao et al. 1987).

He et al. (2001) verified the effects of six senescence promoting factors in Arabidopsis, such as ethylene, abscisic acid, jasmonic acid, brassinosteroid, water deficiency and lack

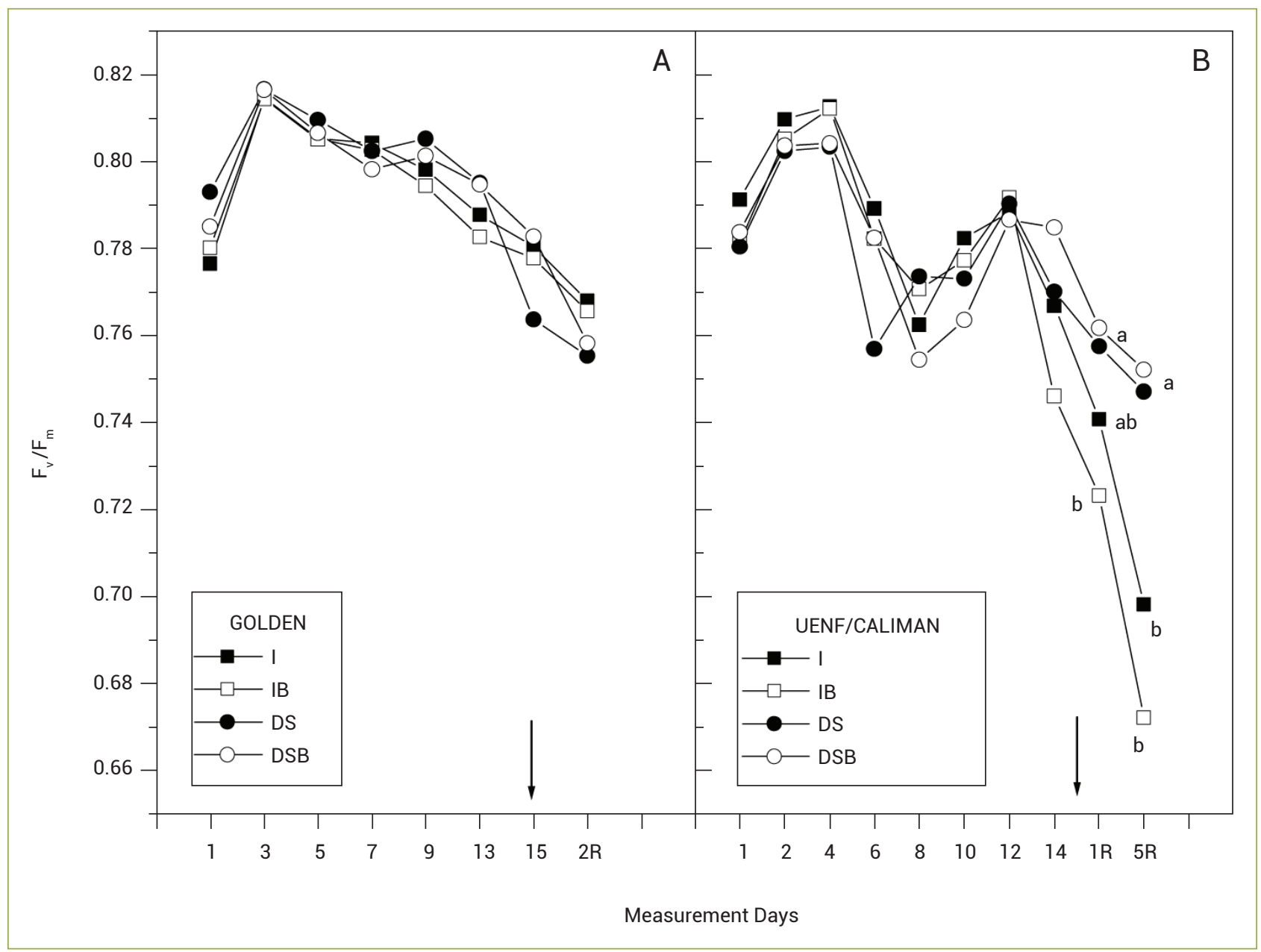

Figure 3. Effects of drought stress and brassinosteroid application on the chlorophyll fluorescence of leaves (LEAF 1) of genotypes Golden (A) and UC 01 (B). Arrow indicates rewatering day and SAB application. R means days after re-watering. (I: irrigated, IB: irrigated with brassinosteroids, DS: Drought stress, DSB: Drought stress with brassinosteroids). Means followed by the same letters are not significantly different, Tukey test, $5 \%$. 
of light to determine the mechanism of leaf senescence. These authors noticed the importance of each of these factors and observed that the application of exogenous epibrassinolide induced the expression of a gene reporter in four enhancer trap lines of Arabidopsis. These results suggest that brassinosteroids play an important role in the activation of senescence. It is well established that brassinosteroid by itself, as well as in synergy with auxins, induce ethylene production (Gomes 2011). On the other hand, Carvalho et al. (2013) verified that jasmonic acid and brassinosteroid as well as the interaction between light and these hormones do not appear to modulate chlorophyll metabolism during senescence.

Molecular and genetic studies identified specific genes in the ethylene biosynthetic pathway that are activated by BS, helping to understand how BS affect the biosynthesis of ethylene and gene expression (Müssig et al. 2002). Brassinosteroids enhance the biosynthesis of ethylene in the reaction of 1-aminociclopropane1-carboxylic acid synthesis from the S-adenosyl methionine (Schlagnhaufer et al. 1984). Brassinosteroids stimulated the biosynthesis of ACC and ethylene in the primary roots of maize. It was exogenously applied to the root, stimulating the release of ethylene and increased the activity of ACC oxidase in a dose-dependent manner (Lim et al. 2002).

Ethylene does not induce senescence alone, because ABA is the trigger of senescence. However, once ethylene is present in the tissue, it increases the rate of senescence when the leaf senescence process has already been started. In addition, many genes induced by brassinosteroids encode cell wall loosening enzymes that are related to leaf abscission (Müssig et al. 2002).

In relation to brassinosteroids, the dosage used, the time and the mode of application are very important because they are decisive in the plant response (Gomes 2011). Furthermore, when the plants are not experiencing water deficiency, the application of brassinosteroids tends to delay leaf senescence but in this work with papaya plants, it was not possible to verify the effects of brassinosteroids in the senescence of leaves of plants that have not been subjected to water deficiency.

Fariduddin et al. (2004) verified that the application of homobrassinolide (HBL), kinetin and the association of both plant regulators delayed senescence and abscission in the leaves of Vigna radiata. Kinetin, which is a synthetic cytokinin, is known to delay leaf senescence. These authors suggest that the cumulative effect of both plant regulators would be related to leaf metabolism, the remobilization of metabolites and the delay of senescence and abscission of plant organs.

The $\mathrm{F}_{\mathrm{v}} / \mathrm{F}_{\mathrm{m}}$ in LEAF 1 was greater for both DS and DSB plants in the UC 01 genotype on the last day of evaluation compared to the irrigated plants. The irrigated plants significantly decreased the $\mathrm{F}_{\mathrm{v}} / \mathrm{F}_{\mathrm{m}}$ ratio at the end of the experiment, demonstrating the impairment of the photosynthetic apparatus. However, the analyzed leaves from irrigated plants were already in an advanced age, relative to the other leaves emitted by these plants. In plants subjected to water deficiency, new leaves emerged only after rewatering so the sampled leaves were the main suppliers of photoassimilates for the rest of the plant and to the newest leaves that developed after the end of the stress. The determination of chlorophyll fluorescence in dark-adapted leaves and the calculation of the maximum quantum efficiency of PSII $\left(\mathrm{F}_{\mathrm{v}} / \mathrm{F}_{\mathrm{m}}\right)$ have been frequently used in plants treated with exogenously applied BS (Holá 2011). This parameter was already measured in a large variety of BS-applied plants (Yu et al. 2004, Ali et al. 2008), but the role of brassinosteroids in the regulation of photosystem II is misunderstood. Although brassinosteroids are related to photooxidative protection, in a considerable amount of work, no beneficial effects of brassinosteroids on $\mathrm{F}_{\mathrm{v}} / \mathrm{F}_{\mathrm{m}}$ values in a great variety of species like tomato (Ogweno et al. 2008), cucumber (Yu et al. 2004, Xia et al. 2009) and pepper (Houimli et al. 2008) were found. In spite of stress, all plants from genotype Golden showed $\mathrm{F}_{\mathrm{v}} / \mathrm{F}_{\mathrm{m}}$ values greater than 0.75 , which is not yet considered deleterious for photosynthesis machinery. Only the plants from irrigated treatments of UC 01 genotype showed $\mathrm{F}_{\mathrm{v}} / \mathrm{F}_{\mathrm{m}}$ values lesser than 0.75 , after twelve days of treatment. This fact is related to the ontogeny of this leaf, which was already extensively discussed for the topic, chlorophyll content.

Despite the reports found in the literature on increased biomass in plants subjected to brassinosteroid application (Sairam 1994, Gomes et al. 2006), it was not possible to detect any increase in papaya biomass or leaf area on plants that were sprayed with brassinosteroids, regardless of water stress. Although Kagale et al. (2007) verified that visible morphological changes in response to drought stress, such as leaf wilting, reduction in growth and complete drying of some seedlings were frequently observed in Arabidopsis thaliana and Brassica napus seedlings subjected to drought stress, these effects were considerably reduced in EBR-treated plants (Kagale et al. 2007).

The present study indicated that foliar-sprayed spirostanic analogue of brassinosteroid caused physiological changes related to chlorophyll metabolism, according to leaf ontogeny of two papaya genotypes subjected to water deficiency.

\section{ACKNOWLEDGEMENTS}

This research was supported by $\mathrm{CNPq}$ (Conselho Nacional de Desenvolvimento Científico e Tecnológico) the authors thank CNPq for the fellowships awarded to Mara de Menezes de Assis Gomes, Eliemar Campostrini and Ricardo Bressan-Smith. 


\section{REFERENCES}

Ali Q, Athar HR, Ashraf M (2008) Modulation of growth, photosynthetic capacity and water relations in salt stressed wheat plants by exogenously applied 24-epibrassinolide. Plant Growth Regulation 56:107-116.

Behnamnia M, Kalantari K, Rezanejad F (2009) Exogenous application of brassinosteroid alleviates drought-induced oxidative stress in Lycopersicon esculentum L. General and Applied Plant Physiology 35:22-34.

Campostrini E, Glenn DM, Yamanishi OK (2010) Papaya: Ecophysiology of growth and production. In: DaMatta (ed). Ecophysiology of tropical tree crops. Nova Science Publishers: Inc., Hauppauge, NY. pp. 285-307.

Campostrini E, Glenn DM (2007) Ecophysiology of papaya: a review. Brazilian Journal of Plant Physiology 19:413-424.

Clemente HS, Marler TE (1996) Drought stress influences gasexchange responses of papaya leaves to rapid changes in irradiance. Journal of American Society of Horticultural Science 12:292-295.

Clouse SD, Sasse JM (1998) Brassinosteroids: essential regulators of plant growth and development. Annual Review of Plant Physiology and Plant Molecular Biology 49:427-451.

Carvalho RF, Monteiro CC, Caetano AC, Dourado MN, Gratão PL, Haddad CRB, Peres LEP, Azevedo RA (2013) Leaf senescence in tomato mutants as affected by irradiance and phytohormones. Biologia Plantarum 57:749-757.

Carr MKV (2013) The water relations and irrigation requirements of papaya (Carica papaya L.): a review. Experimental Agriculture 1-14.

Çăg S (2007) The effects of epibrassinolide on senescence in wheat leaves. Biotechnology and Biotechnology Equipment 21:63-65.

Dhaubhadel S, Browning KS, Gallie DR, Krishna P (2002) Brassinosteroid functions to protect the translational machinery and heat-shock protein synthesis following thermal stress. The Plant Journal 29(6):681-691.

Dhaubhadel S, Chaudhary S, Dobinson KF, Krishna P (1999) Treatment with 24-epibrassinolide, a brassinosteroid, increases the basic thermotolerance of Brassica napus and tomato seedlings. Plant Molecular Biology 40:333-342.

Divi UK, Rahman T, Krishna P (2010) Brassinosteroid-mediated stress tolerance in Arabidopsis shows interactions with abscisic acid, ethylene and salicylic acid pathways. BMC Plant Biology 10:151.

Fariduddin Q, Ahmad A, Hayat S (2004) Responses of Vigna radiata to foliar application of 28 -homobrassinolide and kinetin. Biologia Plantarum 48:465-468.

Gomes MMA, Campostrini E, Leal NR, Viana AP, Ferraz TM, Siqueira LN, Rosa RCC, Netto AT, Núñez-Vázquez M, Zullo MAT (2006) Brassinosteroid analogue effects on the yield of yellow passion fruit plants (Passiflora edulis f. flavicarpa). Scientia Horticulturae 110:235-240.

Gomes MMA (2011) Physiological effects related to brassinosteroid application in plants. In: Hayat $S$ and Ahmad A (eds). Brassinosteroids: a Class of Plant Hormone, 1st Ed. Dordrecht, Heidelberg, London, New York: Springer. pp.193-242.
He YJ, Xu RJ, Zhao YJ (1996) Enhancement of senescence by epibrassinolide in leaves of mung bean seedlings. Acta Phytophysiologica Sinica 22:58-62.

He Y, Tang W, Swain JD, Green AL, Jack TP, Gan S (2001) Networking senescence-regulating pathways by using Arabidopsis enhancer trap lines. Plant Physiology 126:707-716.

Holá D (2011) Brassinosteroids and photosynthesis. In: Hayat S and Ahmad A (eds). Brassinosteroids: a Class of Plant Hormone, 1st Ed. Dordrecht, Heidelberg, London, New York: Springer. pp.143-192.

Houimli SM, Denden M, El Hadj SB (2008) Induction of salt tolerance in pepper (Capsicum anuum) by 24-epibrassinolide. EurAsian Journal of BioSciences 2:83-89.

Iwahori S, Tominaga S, Higuchi S (1990) Retardation of abscission of citrus leaf and fruitlet explants by brassinolide. Plant Growth Regulation 9:119-125

Jager CE, Symons GM, Ross JJ, Reid JB (2008) Do brassinosteroids mediate the water stress response? Physiologia Plantarum 133: 417-425.

Kagale S, Divi UK, Krochko JE, Keller WA, Krishna P (2007) Brassinosteroid confers tolerance in Arabidopsis thaliana and Brassica napus to a range of abiotical stresses. Planta 225:353-364

Khripach VA, Zhabinskii V, De Groot AE (2000) Twenty years of brassinosteroids: steroidal plant hormones warrant better crops for the XXI Century. Annals of Botany 86:441-447.

Krishna P (2003) Brassinosteroid-mediated stress responses. Journal of Plant Growth Regulation 22:289-297.

Li JM, Nagpal P, Vitart V, McMorris TC, Chory J (1996) A role for brassinosteroids in light dependent development of Arabidopsis. Science 272:398-401.

LiKR, Wang HH, Han G, Wang QJ, Fan J (2008) Effects of brassinolide on the survival, growth and drought resistance of Robinia pseudoacacia seedlings under water-stress. New Forests 35:255-266.

Lim SH, Chang SC, Lee JS, Kim SK, Kim SY (2002) Brassinosteroids affect ethylene production in the primary roots of maize (Zea mays L.). Journal of Plant Biology 45:148-153.

Lim PO, Kim HJ, Nam HG (2007) Leaf senescence. Annual Review of Plant Biology 58:115-136.

Mahouachi J, Arbona V, Gómez-Cadenas A (2007) Hormonal changes in papaya seedlings subjected to progressive water stress and re-watering. Plant Growth Regulation 53:43-51.

Mahouachi J, Socorro AR, Talon M (2006) Responses of papaya seedlings (Carica papaya L.) to water stress and re-hydration: growth, photosynthesis and mineral nutrient imbalance. Plant Soil 281:137-146.

Mahouachi J, Argamasilla R, Gómez-Cadenas A (2012) Influence of exogenous glycine betaine and abscisic acid on papaya in responses to water-deficit stress. Journal of Plant Growth Regulation 31:1-10. 
Malo SE, Campbell CW (1986) The Papaya. Gainesville: University of Florida, Cooperative Extension Service Fruits Crops Fact Sheet FC.

Mandava NB (1988) Plant growth-promoting brassinosteroids. Physiology and Plant Molecular Biology 39:23-52.

Marler TE, George AP, Nissen RJ, Andersen PC (1994) Miscellaneous tropical fruits. In: Schaffer B, Andersen PC (eds). Sub-tropical and tropical crops. Handbook of environmental physiology of fruit crops, Vol.2. Boca Raton: CRC Press. pp.199-224.

Müssig C, Altmann T (1999) Physiology and molecular mode of action of brassinosteroids. Plant Physiology and Biochemistry 37:363-372.

Müssig C, Fischer S, Altman T (2002) Brassinosteroid-regulated gene expression. Plant Physiology 129:1241-1251.

Nakashita H, Yasuda M, Nitta T, Asami T, Fujioka S, Arai Y, Sekimata K, Takatsuto S, Yamaguchi I, Yoshida S (2003) Brassinosteroid functions in a broad range of disease resistance in tobacco and rice. The Plant Journal 33(5):887-898.

Nemhauser JL, Hong F, Chory J (2006) Different plant hormones regulate similar processes through largely nonoverlapping transcriptional responses. Cell 126:467-475.

Noodén, LD (1988) Senescence and aging in plants In: Noodén LN, Leopold AC, editors. The phenomenon of senescence and aging. San diego: Academic Press. pp. 1-50.

Ogweno JO, Song XS, Shi K, Hu WH, Mao WH, Zhou YH, Yu JQ, Nogues S (2008) Brassinosteroids alleviate heat-induced inhibition of photosynthesis by increasing carboxylation efficiency and enhancing antioxidant systems in Lycopersicon esculentum. Journal of Plant Growth Regulation 27:49-57.

Rodríguez CMR, Zullo MAT, Queiróz HM, Azevedo MBM, Becerra EA, Manchado FC (2006) The preparation of spirostanic analogues of brassinolide and castasterone. Polish Journal of Chemistry 80:637-646.

Sairam RK (1994) Effects of homobrassinolide application on plant metabolism and grain yield under irrigated and moisture stress conditions of two wheat varieties. Plant Growth Regulation 14:173-181.

Schlagnhaufer C, Arteca RN, Yopp JH (1984) Evidence that brassinosteroid stimulates auxin-induced ethylene synthesis in mung bean hypocotyls between S-adenosylmethionine and 1-aminocyclopropane 1-carboxylic acid. Physiologia Plantarum 61:555-558.
Smart CM (1994) Gene expression during leaf senescence. New Phytologist 126:419-448.

Sugiyama K, Kuraishi S (1989) Stimulation of fruit set of "Morita" navel orange with brassinolide. Acta Horticulturae 239:345-348.

Torres Netto A, Campostrini E, Oliveira JG, Yamanishi OK (2002) Portable chlorophyll meter for the quantification of photosynthetic pigments, nitrogen and the possible use for assessment of the photochemical process in Carica papaya L. Brazilian Journal of Plant Physiology 14:203-210.

Torres Netto A, Campostrini E, Azevedo LC, Souza MA, Ramalho JC, Chaves MM (2009) Morphological analysis and photosynthetic performance of improved papaya genotypes. Brazilian Journal of Plant Physiology 21:209-222.

Vardhini BV, Rao SSR (2002) Acceleration of ripening of tomato pericarp discs by brassinosteroids. Phytochemistry 16:843-847.

Xia XJ, Huang LF, Zhou YH, Mao WH, Shi K, Wu JX, Asami T, Chen Z, Yu JQ (2009) Brassinosteroids promote photosynthesis and growth by enhancing activation of Rubisco and expression of photosynthetic genes in Cucumis sativus. Planta 230:1185-1196.

Yu JQ, Huang LF, Hu WH, Zhou YH, Mao WH, Ye SF, Nogués S (2004) A role for brassinosteroids in the regulation of photosynthesis in Cucumis sativus. Journal of Experimental Botany 55:1135-1143.

Zhang MC, Zhai ZX, Tian XL, Duan LS, Li ZH (2008) Brassinolide alleviated the adverse effect of water deficits on photosynthesis and the antioxidant of soybean (Glycine max L.). Plant Growth Regulation 56:257-264.

Zhao YJ, Luo WH, Wang YQ, Xu RJ (1987) Retarding effects of brassinolide on maturation and senescence of hypocotyls segments of mungbean seedlings. Acta Physiologica Sinica 13:129-135.

Zhao YJ, Xu RJ, Cuo WH (1990) Inhibitory effects of abscisic acid on epibrassinolide-induced senescence of detached cotyledons in cucumber seedlings. Chinese Science Bulletin 35:928-931.

Zullo MAT, Adam G (2002) Brassinosteroids phytohormonesstructure, bioactivity and applications. Brazilian Journal of Plant Physiology 14:143-181. 